\title{
Agricultural Innovation System: Case of Cassava Producers in Kajo-Keji, South Sudan
}

\author{
James Drfoun Amol Ajak ${ }^{1, ~ *, ~ K u r s a t ~ D e m i r y u r e k ~}{ }^{2}$ \\ ${ }^{1}$ Department of Agricultural Economics, Upper Nile University, Juba, South Sudan \\ ${ }^{2}$ Department of Agricultural Economics, Ondokuz Mayis University, Samsun, Turkey
}

Email address:

drfounjames@gmail.com (J. D. A. Ajak), Kursatd@omu.edu.tr (K. Demiryurek)

*Corresponding author

\section{To cite this article:}

James Drfoun Amol Ajak, Kursat Demiryurek. Agricultural Innovation System: Case of Cassava Producers in Kajo-Keji, South Sudan. American Journal of Agriculture and Forestry. Vol. 5, No. 4, 2017, pp. 94-101. doi: 10.11648/j.ajaf.20170504.13

Received: May 23, 2017; Accepted: June 2, 2017; Published: June 9, 2017

\begin{abstract}
The purpose of this paper was to analyze the innovation system of cassava producers related to "Food, Agribusiness and Rural Markets" (FARM) project. Socioeconomic and farm characteristics and information systems of farmers covered by FARM project and farmers not covered by FARM project members were compared and the relations between these characteristics and the innovations score were analyzed. Farmers covered by FARM project and not covered had significant differences in land preparations information sources, seed information sources and fertilizers usefulness. The results indicated that the age of farmers, land preparation information score, agricultural experience, cassava yield, number of family household, number of labor in the farm, number of family workers and casual workers were positively correlated with innovation score. Innovativeness of farmers classified according to their innovation score to less innovative and innovative. The two groups were tested with age, agricultural experience, family household, family workers in the farm, access to agricultural information, access to market and marketing experience and found significant with their innovativeness. It shows that those factors were important to consider it to the innovativeness of cassava farmers in the Kajo-keji. Recommendations for further development of cassava and strong collaboration among the stakeholders, public and private institutions is needed to encourage conventional cassava farmers to adopt modern cassava farming innovations can be suggested.
\end{abstract}

Keywords: Agricultural Innovation System, Innovation Score, Stakeholders, Cassava, Kajo-Keji, South Sudan

\section{Introduction}

Sustainable cassava production growth in South Sudan in general and kajo-keji in particular requires increasing availability of technologies, farm inputs and services on to match the high demand for cassava products. These demands lead to new thinking of agricultural development and production into the chain of activities and interventions required up to consumption level [1]. This requires the participation of all relevant stakeholders, individuals and organizations, in the process of the production. This displays the need for different framework and institutional arrangement to conduct research for development. To be really effective, needs Innovation Systems Approach (ISA), to be integrated into the cassava production process.
Agricultural Innovation System approach is describing the process of technological innovation and the interactions between actors and the stakeholder in production process, which create network to adoption of production activities. These interactions and associated components lead to "innovation systems." Innovation systems can be comprehended by finding out what is within the institutional combination, what is local and what is external. Open systems are being required in which new actors and institutions are regularly being made, modified, and adapted to suit the changes of scientific and technological creation. The concept of network gives a suitable framework for leading the idea of stakeholders, and their interaction, evolution over time, and recent structures. In some countries the innovation system can be different across localities. Local variations in agricultural innovation levels, technology, methods, ideas adoption and diffusion, and the institutional 
combinations are significant features of all countries [2]. An innovation system can be defined as a network of organizations, enterprises, and individuals based on bringing up new products, new processes, and new forms of organization into economic usefulness, together with the institutions and policies that affect their behavior and performance. The innovation systems concept embraces not only the science suppliers but the totality and interaction of actors involved in innovation.

It extends beyond the creation of knowledge to include the factors affecting demand for and use of information in novel and useful ways. Government, private sector, universities, and research institutions are important parts of a larger system of information and interactions that allows diverse actors with different strengths to come together to bring up common goals in agricultural innovation. In many African countries, the state still plays a key role in directing agricultural production activities. But the private sector is become important player in adopting existing knowledge and applying it to new areas. The innovation systems concept is derived from direct observations of countries and sectors with strong records of innovation. It has been applied to agriculture in developing countries only recently, but it appears to offer exciting opportunities for understanding how a country's agricultural sector can make better use of new information and for designing alternative interventions that go beyond research system investments. The study of technological change in agriculture has always been concerned with systems, for instances the applications of the National Agricultural Research System (NARS) and the Agricultural Knowledge and Information System (AKIS) approaches. However, the innovation systems literature is a major transfer from the traditional studies of technological change that were often used in NARS- and AKIS-driven research. The NARS and AKIS approaches, for example, emphasize the role of public sector research, extension, and educational organizations in generating and disseminating new technologies. Interventions based on these approaches traditionally focused on investing in public organizations to improve the supply of new technologies.

In agricultural innovation system approach, the main restriction on the use of technical information is not just supply or availability, but also the limited ability of innovative agents to absorb it. Even though technical information may be freely accessible, institutions have to invest heavily to develop the ability to use the information. While both the NARS and AKIS frameworks made critical contributions to the study of technological change in agriculture, they are now challenged by the increased changing in agriculture sector. The agricultural innovation system shows key actors and their interactions that enable farmers to obtain access to technologies.

\section{Conceptual Framework for AIS}

This research, applied the analysis of innovation system in order to comprehend how cassava farmers in the study area obtain access to innovations. In this section terms such as national agricultural research system, transfer of technology, agricultural knowledge information system, agricultural innovation system, are first presented and discussed. Second, how to functionalize the agricultural innovation system approach on cassava production are presented. Third, the findings of previous studies are reviewed and their relevance to the current research is considered. An innovation had been defined as adopting new or existing institutional or local knowledge to a new situation with an economically and socially appropriate [3]. It points that an innovation can be idea, methods which have been used before but it changes to a new way of using to increase productivity or to solve an agricultural problem.

There are remarkable changes in the concept of agricultural innovation system overtime these changes have been in period that can be classified into four transitions. The four transitions can be stated as follows:

1. National Agricultural Research System (NARS)

2. Transfer of Technology (TOT)

3. Agricultural Knowledge and Information System (AKIS)

4. Agricultural Innovation System (AIS).

National Agricultural Research System concept was used of development effort on strengthening research supply by providing infrastructure, capacity management, and policy support at the national level. In the 1980s period, NARS was majorly used in agricultural sector. The concept is classical linear which is that agricultural research through technology transfer, leads to technology adoption and growth in productivity [4]. The effectiveness of this concept depends on the adoption of such technology transfer. However, this concept is not specifically linked to technology users and other actors thereby possess the tendency of not reflecting the key actors' needs and changing circumstances of the sector [4].

In the mid $1980 \mathrm{~s}$ to late $1990 \mathrm{~s}$, technology transfer concept was focused. This concept focused on greater participation of farmers and extension agents. It involves training the farmers, allow farmers to practice and visit farmer's farms to ascertain the adoption of the technology. The objective of TOT system was based on reforming and improving upon the effectiveness of conventional agricultural extension for agricultural development. The effectiveness of this concept also depend on technology adoption and in fact enhances technology transfer and adoption that allows farmers feedback. The limitation of TOT lies in the role involvement and dependency of extension agents and lack of other network and actor's interaction. Röling in 1988 criticized the technology transfer model and developed Agricultural Information Systems (AIS) [5]. Agricultural Knowledge and Information systems (AKIS) link people and organizations to promote mutual learning and to generate, share and use agriculture related technology, knowledge and information. This concept integrates farmers, agricultural educators, researchers, and extension staff to harness knowledge and 
information from various sources for improved livelihoods [4]. Farmer as a key actor is at the heart of the knowledge triangle formed by education, research and extension. However, the concept's focus is restricted to actors and processes in the rural environment with limited attention to other institutional actors and factors [4]. Innovation in agricultural sector to this transition has been dominated by the narrow approach of technology transfer and adoption theory. The innovation systems concept values the capacities and processes emphasized in the AKIS frameworks, including channels that give farmers access to information, and well-resourced and up to date scientific research and training organizations. The innovation systems concept goes further in recognizing a broader range of actors and disciplines/sectors involved in innovation, particularly the private sector in its many guises along the value chain. Innovation systems analysis recognizes that creating an enabling environment to support the use of knowledge is as important as making that knowledge available through research and dissemination mechanisms [4]. This concept offers a way of strengthening the capacity to create, diffuse, and use knowledge in providing solution to existing problems [4]. The concept of AIS is considered to have great potential to add value to previous concepts of agricultural research systems and growth.

For example, in (NARS) is drawing attention to the totality of all actors needed for innovation and growth and purposed on planning capacity for agricultural research, technology development, and technology transfer with lack of role of the market. In Agricultural Knowledge and Information Systems (AKIS) according to [6] there is a way of strengthening communication and knowledge delivery services to people in the rural sector with outcome of technology adoption and innovation hence the role of the market is still low. In agricultural innovation systems (AIS) there are possibilities of strengthening communication and knowledge delivery services to people in the rural sector out coming different types of innovation and making interaction and innovation among stakeholders and gives strong role of market in the system. Considering the role of the private sector (organizations, traders and companies) and the role of public sector (government, research centers and consumers) in cassava production and the importance of interactions within actors in production of cassava Figure 1. It emphasizes that the approaches used before to improve cassava production was not able to solve the problems facing it and the outcomes was technology and knowledge generation and adoption rather than the strengthening of research systems and their outputs [6]. Demiryurek (2014) noted legion analytical methods for example information transfer method, information system methods and agricultural knowledge and information system models, hence it found that such frameworks have limitation and weak points. Therefore, agricultural innovation system approach come forth as suitable way to analysis in this research [3].

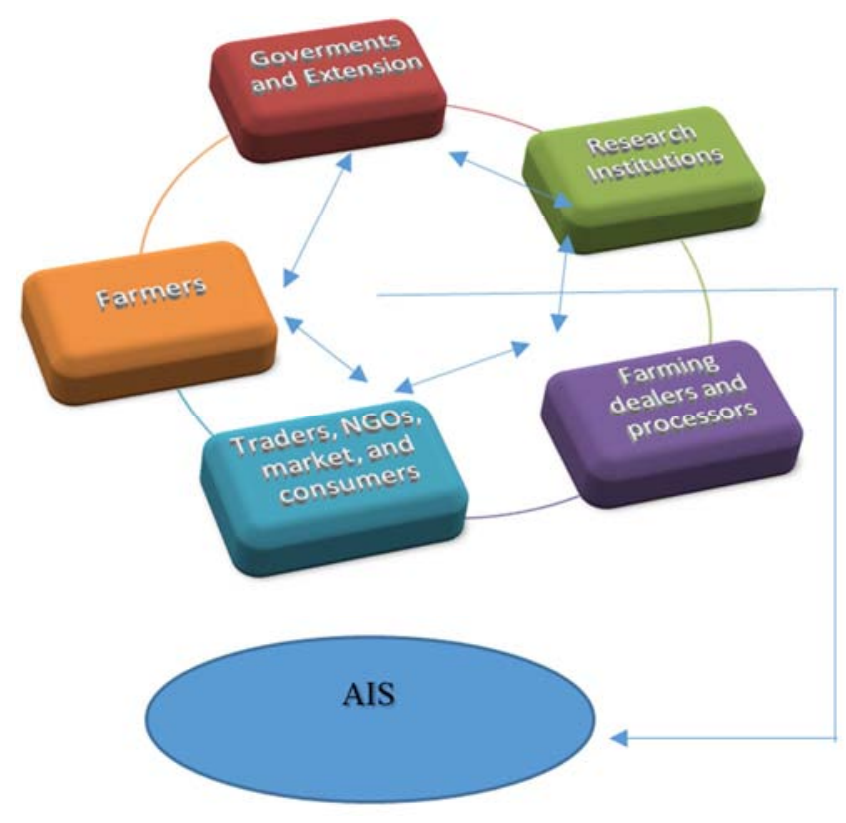

Figure 1. Applying AIS on cassava production.

\section{Research Methods}

\subsection{Study Area}

Kajo Keji is one of Central Equatoria state counties, home of the Bari-speaking Kuku. It is bounded to the west, north and east respectively by Yei, Juba and Magwi counties, and Uganda to the south. Its five payams, Kangepo I, Kangepo II, Lire, Livolo, and Nyepo, are all served by foreign agencies. This county has faced consequences of many conflicts: civil war, (1955-72, 1983-2005), local disputes, and northern Uganda's troubles. The land of Kajo-Keji has been wellknown for its abundance in cattle, goats and chickens [7].

USAID established FARM project in 2010 to increase agricultural production, build rural markets, and improve public and private capacity in South Sudan to develop commercial smallholder agriculture. The $\$ 54$ million project operates in Eastern, Central and Western Equatoria, across the broad swath of high-potential agricultural land known locally as the Greenbelt. The FARM Project contributes to South Sudan's goals of achieving food self-sufficiency, reducing poverty, promoting economic growth through higher agriculture productivity and market creation [7].

\subsection{Interviews and Sampling}

In this study, multiple data collection techniques were used for the purpose of the study, cassava farmers in Kajo-keji was developed for data collection. The sample for this study consists of a sample of 80 cassava farmers 38 covered by FARM project from 1000 farmers under FARM project strengthened through increased technical and managerial capacity of leadership and 42 not covered by FARM project was selected for the survey. The research instrument was in the form of questions. Variables were like socioeconomic information such as age, education level, agricultural experience, farm size, source of income (on-farm and off- 
farm income) and the membership to FARM project.

\subsection{Calculation of Innovation Scores}

Innovation score in this work used basic idea of the Innovation Index is to assign a single numerical value to the set of innovations of every farmer such numerical valuation must assign higher numbers to innovations that push the technological frontier or to innovations that are relatively rare within the sub sector, here it is refers to the degree of adoption of a particular innovation among the farmers [8].

Demiryurek et al., (2014) developed innovation sustainability index of Dasagupta, (1968) by using not only number of innovation but also included years of adoption. The increases of innovation index value rise the sustainability of innovation the farmer has adopted. Therefore, farmers whose have higher index value can be said are more innovative [9].

In this study the Innovation Score of cassava farmer's in Kajo -keji is calculated as:

Inoovation Scores $=$ Number of years of adoption $\times$ Number of adopted innovation Total of innovation

\subsection{Statistical Tests}

Three statistical tests were used in this research. First, the Student $t$ test was used to compare the differences of socioeconomic variables between the two kinds of farmers covered and not covered by FARM project. Second, the
Correlation Coefficients (r) test was used to statistically explore the association between the Total Innovation Score and some selected socioeconomic variables. Third it considered the effects of the innovativeness of farmers (being innovative and less innovative) compared to with also some socio economic variables of farmer.

\section{Results and Discussion}

Comparing the socioeconomic characteristics of cassava farmers is necessary to develop farmer's innovativeness and to analyze the innovation system to the both group covered and not covered by FARM project. In this study similarity was discovered in terms of age, educational level, farming experience, farm size, agricultural income and land allocated for cassava production. Because of the demographic structure of the study area, generally elders prefer staying in the villages and relatively younger people go to big towns to find a work. The reason for educational similarities could be because of furthermost of the farmers used to drop education in early age. The similar farming experience, farm size, agricultural income and land allocated for cassava production can be explain that the selection criteria in nominating farmer by FARM project don't consider these characteristic in their policy. In conclusion, age educational level, farm size, agricultural income, and land allocated for cassava production did not function as discrimination.

Table 1. Comparing the socioeconomic characteristics of cassava farmers.

\begin{tabular}{|c|c|c|c|c|c|}
\hline \multirow{2}{*}{ Variables } & \multicolumn{2}{|c|}{ Farmers not covered by FARM project } & \multicolumn{2}{|c|}{ Farmer covered by FARM } & \multirow[t]{2}{*}{ P-Value } \\
\hline & Mean & Std.Dev & Mean & Std.dev & \\
\hline Farmer's age & 43.81 & 9.766 & 43.87 & 7.980 & 0.120 \\
\hline Farming experience & 19.45 & 10.405 & 20.05 & 9.409 & 0.545 \\
\hline Farm size & 16.12 & 9.711 & 13.16 & 8.541 & 0.153 \\
\hline Agricultural income & 76.88 & 13.873 & 76.45 & 13.542 & 0.975 \\
\hline Land allocated to cassava & 5.86 & 3.586 & 5.00 & 2.092 & 0.202 \\
\hline
\end{tabular}

Agricultural information sources and processing information sources for cassava producers in Kajo-keji were found significant most of farmer not covered by FARM project generally got agricultural information from County
Agricultural Department Extension and farmers covered by FARM project got their information from FARM project Extension this showed the essential role of the agricultural information to increase the productivity.

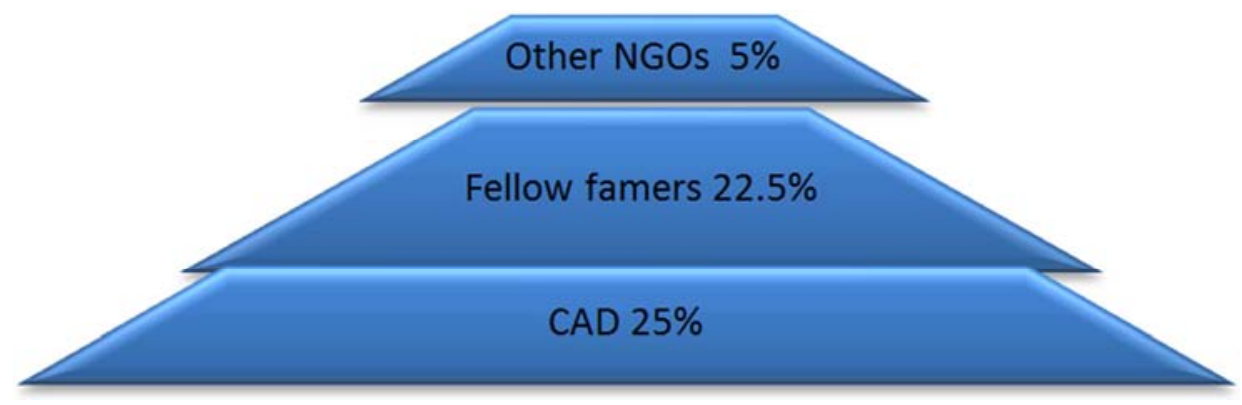

Source of agricultural information for farmer not covered by FARM project 


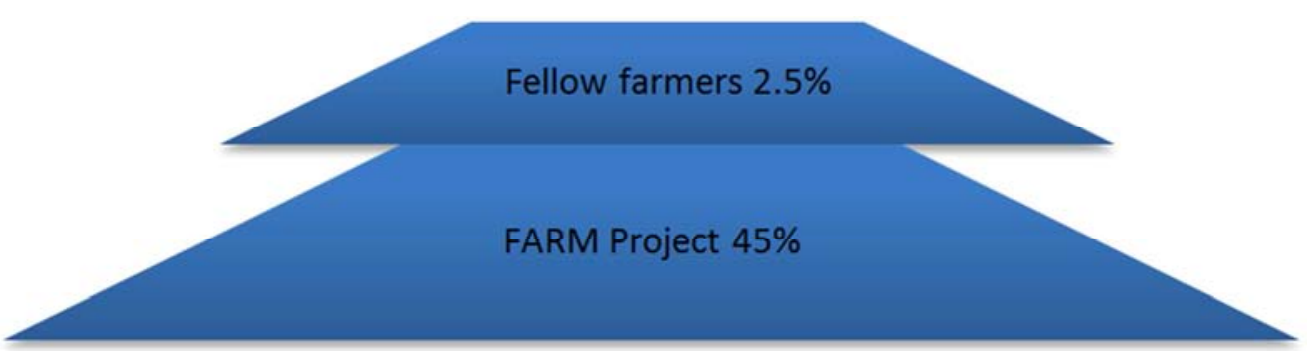

Source of agricultural information for farmers covered by FARM project

Figure 2. Sources of agricultural information of cassava producers in Kajo-keji.

\subsection{Correlation Between Socioeconomic Variables and Innovation Scores}

Measuring agricultural innovation is a notoriously difficult task, in order to calculate the innovation score in this work we used innovation index. The basic idea of the Innovation Index is to assign a single numerical value to the set of innovations of every farmer such numerical valuation must assign higher numbers to innovations [8].

Demiryurek et al., (2014) used innovation sustainability index where is showing the adopted applied practices by the farmer nevertheless the year's farmer adopted the innovation is considered. Hence when the innovation index value increases the sustainability of innovation that farmer has been adopted increase consequently. Therefore, farmers whose have higher index value can be said are more innovative [9].

Innovations scores were designed to calculate the innovation index for the six innovations (innovation of planting improved seed, land preparation innovations, applying innovation of fertilizers, pesticides innovation, processing innovation and innovation on cassava storing.

The correlation analysis results on innovation scores and some socioeconomic variables showed positive correlation with the cassava farmer's age, family household and number of family workers in the farm, cassava production, agricultural experience, labor in the farm, causal workers in the farm and land preparations. Cassava producers age, family household, numbers of family worker in the farm and casual workers in the farm ( 0.377 to 0.599$)$ was indicating to have the highest correlation with the innovation score. The land preparation information score, labor in the farm, cassava production and agricultural experiences found to have the lowest correlation ( 0.036 to 0.281$)$ with innovation scores. Therefore, the positive association between the innovation score and socioeconomics implies the role played by FARM project to increase the ability of farmers to be innovative in the cassava production.

Table 2. Correlation between socioeconomic variables and innovation scores

\begin{tabular}{|c|c|c|c|}
\hline \multirow{2}{*}{ Variables } & \multicolumn{2}{|c|}{ Innovation Score } & \\
\hline & r value & p value & \\
\hline Age & $0.599 * *$ & 0.01 & Pearson \\
\hline Cassava production & $0.260 *$ & 0.02 & Pearson \\
\hline Agricultural experience & $0.281 *$ & 0.012 & Pearson \\
\hline Family household & $0.384 * *$ & 0.001 & Spearman \\
\hline Labor in the Farm & $0.251 *$ & 0.025 & Spearman \\
\hline Number of family workers & $0.398 * *$ & 0.001 & Spearman \\
\hline Casual workers & $0.377 *$ & 0.028 & Pearson \\
\hline Land preparation information score & $0.236 *$ & 0.035 & Spearman \\
\hline
\end{tabular}

$* \mathrm{p}<0.05 * * \mathrm{p}<0.01$

\subsection{The Innovativeness of Cassava Farmers}

In this study to test how cassava farmers are innovative they were classified into two group according to the innovation score. Farmers who scored means 11.19 and less were classified to be less innovative and 11.20 and above were classified to innovative according to that 48 of farmers were found less innovative and 32 of farmers were innovative.

According [10] innovations are new ideas, methods, practices or techniques which provide the means of achieving sustained increases in farm productivity, and income. It can be said that innovations originate from agricultural research stations, others from farmers. Farmer's innovativeness refers to the degree to which an individual farmer is relatively earlier in adopting new changes than other members of the society. Innovative cassava farmers in Kajo-keji South Sudan could be defined as, farmers those who have tried or are trying out new but value-adding cassava production or any agricultural production or natural resource management practices, using their own knowledge and wisdom but also through appropriation of outsiders' knowledge, often called scientific. Without contradicting the recognition of local knowledge as an important asset of development, innovative farmers are not those who are using as it used to be during their ancestors' time. Farmers who act on local knowledge and/or outsiders' knowledge - through conducting informal experiments and making the knowledge more usable or better fitting to their own realities. Moreover, farmers who have been trained by extension workers may also be recognized as innovators, when they are dealing with the incoming knowledge/technology by improving it or regardless of their sex, 
wealth status or age) who are trying to add value to existing practices through creative engagement and experimentation and with a passion to seek changes that have economic, social and environmental significance. other important dimension of the concept of "farmer innovation" is that it embraces not only technological innovation, but also new ways of managing livelihood in general. This may include new ways farmers do networking, communication, institution building, information management, marketing, planning and accessing resources in view of improving their agricultural and natural resource conservation activities. In short, this means, farmer innovation is all about new ways of doing agriculture and natural resources management. That newness entails values that may bring changes in quality of life.

Table 3. The innovativeness of farmers compared to socioeconomic characteristics.

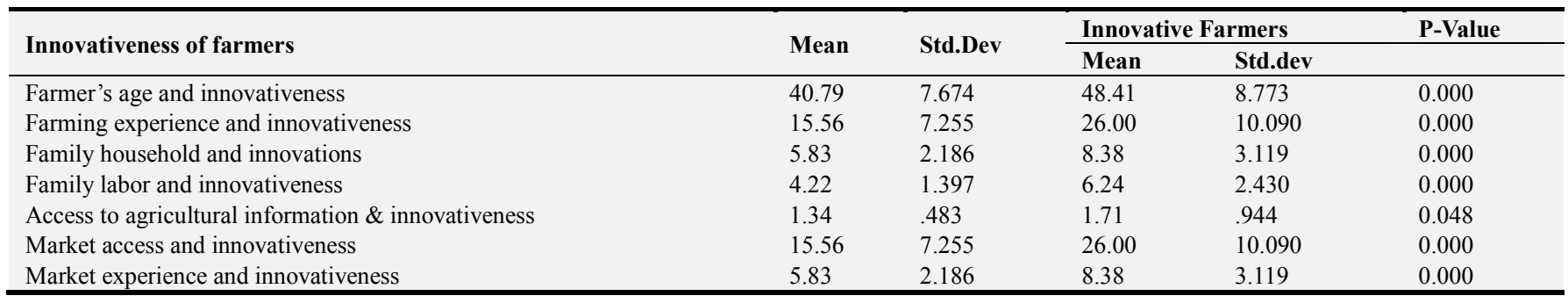

\section{Conclusion and Recommendations}

The study aims to help key players in the private and public sector in producing cassava to make informed decisions on whether to develop the production of cassava production. Kajo-keji area of South Sudan has different cropping systems of over 30 crops grown. The most important and widely grown crop in Kaj-keji is cassava. It is grown by most farmers in the area. Cassava is an important food and famine crop for the people of Equatoria. Socioeconomic characteristics of farmers covered by FARM project and not covered were presented. It was found that there was no significant difference in terms of age, education, off-farm and on-farm income, farming experience, agricultural information sources and markets for farmers covered and not covered by FARM project.

This can be explaining that the authorities of FARM project didn't apply any criteria of selection regarding farmer's socioeconomic characteristic. However, there was significantly different according to land preparation information sources, processing information sources, seed information sources and fertilizers usefulness. It implies the importance of good preparations of land and fertilizers to cassava production. It was found that cassava largely grown for food and as a food reserve crop with surplus going for sale, brewing and very little proportion for animal feed. It is predominantly grown as an intercrop.

The familiar crops grown in combination with cassava are groundnut, maize, beans. Many varieties of cassava are being cultivated in the area, largely at subsistence levels on less than 5 feddan per household. The spread of improved varieties is moving at faster rate in the area. Cassava is constrained by number of problems such as pests and diseases, weeds, lack of market, poor processing technologies, inadequate knowledge, poor infrastructures and roads to both groups of farmers. Concerning agricultural information, it found that cassava farmers in Kajo-keji, the most important sources of cassava planting materials and information sources are the FARM project NGOs, C.A.D and farmers' own farmers. Involvement of the stakeholders in cassava production it found that there was weak participation from the government and traders and somehow involvement from NOGs (FARM project). To increase cassava production, the stakeholders in the area needed to work in platform.

In term of technologies used by farmers it was found that they have the same local and indigenous tools. The policy makers can consider in their policy focusing the subsidies to cassava producers based on their innovativeness. Due to the weak infrastructure and security problems along the roads to juba and other parts of the country famers have problems in marketing their products. It assures that to develop cassava production in whole South Sudan good roads and security are required. The study showed that farmers who were more aged, more agricultural experience, had access to agricultural information, had access to markets and more marketing experience are more innovative. This characteristic could be used when putting polices by the institution dealing with cassava production in the whole South Sudan.

Due to that also FARM project policy should take the consideration of those factors when putting future policy to cassava production. Also the role of county agricultural department of extension was found weak it implies that the government need to make more improvement in agricultural extension works through giving more support to the staff working in the fields. Farmer's personal and farm characteristics when compared to their membership to FARM project implies that the policy of FARM project didn't consider those factors. However, it found that those factors play important role in farmer's innovativeness and can be considered. Significant differences and positive correlation observed between farmer's innovation score with respect to socioeconomic characteristics, i.e., age, cassava production, agriculture experience, farm household, labor in the farm, family workers in the farm, and casual workers in the farm. In addition to that significant differences and positive correlation observed between farmer's innovation score and land preparation information score. This implies that those factors are so important to be considered in any policy related to cassava producers in Kajo-keji particularly and South 
Sudan generally. Considering the challenges facing cassava production to innovation system in South Sudan (Kajo-keji) county, it is clear that an importance effort is required if major changes in production, innovation and marketing are to be noticed. There is consequently a need for collaborative work by all concerned stakeholders, i.e., farmers, processors, traders, researchers, development agencies, policymakers, and other government bodies to put in place a system that is productive, sustainable, and profitable in the long run. The subsequent are key areas that need due attention for improving the cassava production to innovation system. Integrating cooperative networking: this needs to be integrated through cooperative networking among NGOs, traders, international research bodies, and government institutions like agricultural extension departments. Agricultural extensions system the Ministry of Agriculture and Forestry (MAF) South Sudan need to improve the government agricultural extension services for cassava improvement programs.

Capacity building and trainings: It found that aged farmers and more experience are more innovative. Their capacity needs to be built through training in modern technologies. Introducing appropriate production and processing technologies: this can be done through extension agents, NGOs operating agricultural programs need to introduce appropriate production and processing technologies to the farmers to enable them maximally utilize the available limited resources. Improvement of infrastructures and capacity building: government of South Sudan needs to put optimum efforts in establishing a functional road network to facilitate trade, not only in cassava but also other agriculture related sectors. In addition, efforts should be directed at reopening research institutions and other training centers in South Sudan. Security improvement: The Government of South Sudan needs to maintain the stability of security situation if cassava crop production is to be strengthened. Both civil war and tribal clashes negatively affect cassava production and productivity.

FARM project programs related to cassava crop can consider in their selection in applying those programs the innovative farmers with more experience and markets experiences. The government need to build up rural markets, most of farmers were having problems in accessing markets due to the poor roads and insecurity in these areas. To have full understanding of cassava innovation system status in South Sudan, further survey is needed to be carried out in all the area producing cassava in the country.

\section{References}

[1] IITA: IITA 2015. Support to Agricultural Research for Development of Strategic Crops in Africa (SARD-SC) Project Farmers' Guide to Cassava Cultivation. In: www.iita.org. (Accessed May 2015) Available at: HYPERLINK "http://docplayer.net/31031744-Farmers-guide-to-cassavacultivation.html".

[2] Vasco M., C., Nico, V.: Input Diffusion and the Evolution of
Production Networks. Cambridge and CEPR UCLA, NBER, and CEPR First Version (2014).

[3] Demiryurek, K.: gricultural Knowledge and Innovation Systems and Social Communication Networks. Ondokuz Mayıs University. (2014).

[4] World Bank: Enhancing Agricultural Innovation: How to Go Beyond the Strengthening of Research Systems. World Bank, Washington, DC (2006).

[5] Röling, N.: Extension Science: Information systems in agricultural development. Cambridge University Press, Cambridge (1988).

[6] Demiryurek K., E.: Agricultural information systems and communication networks: the case of dairy farmers in the Samsun province of Turkey. Information Research 13(2), 25 (2008).

[7] USAID: Food, Agriculture And Rural Markets (FARM) Project Mid - Term Evaluation Report. (2012).

[8] Ariza C. R., D.: Measuring Innovation in Agricultural Firms: A Methodological Approach. The Electronic Journal of Knowledge Management 11(3), 185-198 (2013).

[9] Demiryurek et al, K.: Effect of Dairy Cattle Breeders' Association (DCBA) Membership on Sustainability of Innovations in Samsun Province of Turkey. In: Conference: 2nd ICSAE 2015 İnternational Conference on Sustainable Agriculture and Environment, Turkey, Konya, pp.1-4 (2015).

[10] Demiryurek, K.: Agricultural Systems Volume 103, Issue 7, September 2010, Pages Cover image Analysis of information systems and communication networks for organic and conventional hazelnut producers in the Samsun province of TurkeyKursat Demiryurek, Show more https://doi.org/10.1016/j.agsy.2010.04.002. Agricultural Systems 103(7), 444-452 (September 2010).

[11] Amankwah K., K.: Diagnosing constraints to market participation of s mall ruminant producers in northern Ghana: an innovation systems analysis. Life Science 60(63), 37-47. (2012).

[12] Asogwa B. C., U.: Technical Efficiency Analysis of Nigerian Cassava Farmers: A guide for Food Security Policy. In: International Association of Agricultural Economists Conference, Gold Coast, Australia (2006).

[13] Ani, J.: Relationship between socio-economic characteristics of rural women farmers and their adoption of farm technologies in southern Ebonyi State, Nigeria. nternational Journal of Agriculture \& Biology 06(5), 802-805 (2010).

[14] Carlsson B., S.: On the nature, function and composition of technological systems. Evol. Econ 1, 93-118 (1991).

[15] Chi T., Y.: Factors affecting farmers' adoption of technologies in farming system: A case study in OMon district, Can Tho province, Mekong Delta. Japan International Research Center for Agricultural Sciences, 99-100 (2002).

[16] Demiryurek, K.: Information systems and communication networks for agriculture and rural people. Agric. Econ 56(5), 209 (2010).

[17] Dusenbury, A.: Post-conflict returnee reintegration: a case study of South Sudan and the livelihood approach. (2013).

[18] FAO: Farmer Experimentation and Innovation. A case study of knowledge generation. (1996). 
[19] FAO: Background paper for the Competitive Commercial Agriculture in Sub-Saharan Africa (CCAA) Study Cassava: International market profile., 11 (2007).

[20] FAO: Development of Agriculture in South Sudan., FAO (2011).

[21] FAO: Crop Planting Assessment Mission to Western and Central Equatoria Republic of South Sudan April 2014 Report 1 in preparation for the Crop and Food Security Assessment Mission (CFSAM)., FAO, Rome (2011).

[22] FAO: Save and Grow: Cassava A guide to sustainable production intensification. (2013).

[23] FAO-WFP.: Crop and Food Security Assessment Mission to South Sudan. (2014).

[24] Hall, A.: Capacity development for agricultural biotechnology in developing countries: an innovation systems view of what it is and how to develop it. Journal of International Development, 17(5), 611-630 (2005).

[25] Hall, A.: Public-private sector partnerships in an agricultural system of innovation: Concepts and challenges. nternational Journal of Technology Management \& Sustainable Development 5(1), 3-20 (2006).

[26] IITA: Southern Sudan, Equatoria Region, Cassava Baseline Survey Technical Report. (2007).
[27] Kilelu, C., Klerkx, L.: Unravelling the role of innovation platforms in supporting co-evolution of innovation. Agricultural Systems(118), 65-77 (2013).

[28] Klerkx, L.: Adaptive management in agricultural innovation systems: the interactions between innovation networks and their environment. Agricultural Systems 103 (2010).

[29] Klerkx, L.: Establishment and embedding of innovation brokers at different innovation system levels: Insights from the Dutch agricultural sector. Technological Forecasting and Social Change 76(6), 849-860 (2009).

[30] Klerkx, L.: Matching demand and supply in the agricultural knowledge infrastructure: Experiences with innovation intermediaries. Food Policy 33(3), 260-276 (2008).

[31] UNMISS: Kajo-Keji, South Sudan: General Information., United Nations Mission in Sudan (UNMISS) (2010).

[32] USAID: Food, Agriculture and Rural Markets (FARM) project. mid - term evaluation report, USAID (2013).

[33] World Bank: Agricultural Innovation Systems: An Investment Sourcebook. Elsevier, Washington, DC (2012).

[34] World Bank: Enhancing agricultural Innovation: How to Go Beyond the Strengthening of Research Systems. World Bank, Washington, DC (2006). 